\title{
The environmental risk as a culture in the Sinos Valley, Brazil
}

\author{
VALDIR PEDDE ${ }^{1}$, JOÃO A. FIGUEIREDO ${ }^{2}$, JOSÉ G. TUNDISI ${ }^{2}$ and CÁTIA A. LENZ ${ }^{3}$ \\ ${ }^{1}$ Programa de Pós-Graduação em Diversidade e Inclusão, Universidade Feevale, \\ ERS 239, 2755, Vila Nova, 93352-000 Novo Hamburgo, RS, Brasil \\ ${ }^{2}$ Programa de Pós-Graduação em Qualidade Ambiental, Universidade Feevale, \\ ERS 239, 2755, Vila Nova, 93352-000 Novo Hamburgo, RS, Brasil \\ ${ }^{3}$ Fundação de Saúde Pública de Novo Hamburgo, Avenida Pedro Adams Filho, \\ 6520, Operário, 93310-003 Novo Hamburgo, RS, Brasil
}

Manuscript received on April 4, 2013; accepted for publication on February 17, 2014

\begin{abstract}
The proposal of analysis of the social-environmental perception will be developed from the discourse as a constitutive element of reality. The discourse practices and their concretion will be the source of meaning and social-cultural value. Thus, the chosen research method was the qualitative and quantitative case study. In the first part of the text we will recapture a theoretical input by Mary Douglas on risk and culture, as well as on the acceptance of the risks in society. In the second part, we cover a few data of the case of the risks resulting from the tanning industry and on how the society of the "Vale do Rio dos Sinos" relates to these risks. In this article we conclude that risk perception of the population is directly related with past experiences, thus, assigning a meaning to all new events. This meaning is the result of a sociocultural construction. It is worth noting that behind this history, there are basic issues related to population survival, i.e., both the industrialists and workers establish partnerships when the society creates a movement against the leather industry.
\end{abstract}

Key words: environmental risk, risk perception, river pollution, leather footwear industry.

\section{INTRODUCTION}

The article is based on the principle that the contamination of the tanneries as a problem to be developed by sociology is evidenced by its importance in the social and historical formation of the community of the "Vale do Rio dos Sinos" (Sinos Valley - SV) - Brazil. From social sciences, the case of the tanning industry in the Sinos Valley and the real risks represented by catastrophes, especially that which occurred in October 2006,

Correspondence to: Valdir Pedde

E-mail: valpe@feevale.br when more than 100 tons of fish died in the Sinos River, and led to accusations of complicity of this industry, justify the study subject, this disaster was widely reported in the printed media and television services from the whole country ${ }^{1}$; moreover, the relationship of the perception of the risk in values, feelings and beliefs that are characteristic of this concrete society is established.

Following this constructivist approach, based on the social-historical and cultural formation process of the SV and on how this influences personal and institutional decisions in relation to the

\footnotetext{
${ }^{1}$ For additional information about the Environmental Disaster, refer:
} http://g1.globo.com/Noticias/Brasil/0,,AA1408565-5598,00.html and http://sosriodossinos.zip.net/. 
industrial development and with the environmental risks caused by this development. In the case of the tanneries in the SV, even though the strong impact of this industrial activity on the environment and health has been institutionalized or has been recognized by specialists and by responsible organisms, it is not sufficient to change the symbols that have been constructed by the collective along history.

It is established that there is no universal condition in the issue of risks, or rather the perception is conditioned to the external and internal context of the individual. Regarding the case investigated, the aspects of the (external) historical and cultural construction are directly linked to the development of leather and footwear industrialization that have been and are determinant in the attribution of values, principles, perception and inner attitude regarding the risks of this industrial complex.

After all, the social-cultural formation of the SV legitimates the development of the region as a consequence of the progress of the "leatherfootwear" industry; in the background of this history, there are the basic questions of survival of the population, meaning that both the industrialists and the workers establish alliances for the continuity of this industrial segment.

\section{RISK AND CULTURE}

The ethnographic approach of Douglas and Wildavsky in Risk and Culture (1982) has entitled Douglas to be considered as the main reference in the field of anthropology of risk. Douglas' key contribution lies in promoting an approach to risk perception as a cultural construction. The author develops a link between cultural contexts and subjectivity, in which individual attitudes are always bounded by a system of values, ideals and beliefs, which in turn are part of a culture or subculture that serves as a basis for risk assessment.

A key aspect of the theoretical development by Douglas is the formulation of a theory of culture that allows thinking about the social origin of cognitive categories. In Douglas' theory, individuals make use of classification systems according to their position in a given social order. Thus, this is what Bestard proposes in the preface of Risk Acceptability, suggesting that the categories are positions rather than things: they depend on the position in a given social order. He states that Douglas, in Risk and Culture, analyzes the way we construct certain cultural categories based on certain social positions, i.e., the notions of risk are not based on practical reasons or empirical judgments, they are culturally constructed notions that emphasize some aspects of the risk while ignoring others. Thus, a culture of risk is created, which varies according to the social position [relationship] of the actors.

Douglas (1992) attempts to identify how humans distinguish what is from what is not a risk, what is accepted from what is not accepted as a risk. The principle underlying this theory is that risks originate from a collective and cultural construction, which is a product of society and what happens in its history.

In this direction, when raising moral questions on the acceptability of risk, Douglas (1996) assumes that one should not question whether a risk is acceptable, but rather ask what project of society one wishes and expects for the future, which depends on policies that are neither defined in a shared manner nor based on a distribution of risks to groups that endure greater privations. The author addresses a technical problem inherent in the risk analysis: the difficulty in balancing the risks and benefits. For example, she indicates that ethical issues are critical when planning the transfer of hazardous industries from a densely populated to a less populated area, whatever the reason for such a transfer (because the population is most in need of employment, income, etc.).

In relation to social justice, the risk rests on the value that people give to certain facts. A major problem with this approach is that sometimes the acceptability of risk is in contradiction with the 
concept of equity, giving rise to the following questions: should a region with unfavorable conditions remain in such conditions, or is it fair that people should accept to live close to an "industrial park" for the alleged economic advantages involved, i.e., is being exposed to contamination a valid condition to secure a job and ensure survival? In this sense, according to Douglas (1996), public perception regarding risk policies will be determined by publicly accepted ideas about justice. The author argues that acceptability functions as social conventions (common discourses and ideas), in which "what is fair" is directly related to what is accepted (or not) as a risk. This approach should also be important when assessing the potential of the community of the Sinos Valley to promote injustice frames within the leather industry complex.

In addition, for Douglas, the sum of shared values and principles is used to justify a behavior, i.e., the cognition-risk ratio is also influenced by culture, occurring in public institutions where the values and behaviors related to institutional life are maintained.

Risks of low probability or involving the familiar expression, in most cases, are underestimated; by contrast, what impacts in most cases are the risks made public by the media. In this sense, the concept of cognitive immunity may help us understand why tannery workers have not promoted actions or manifested themselves against the hazardous work they are performing or why the neighboring community accepts such industrial development despite numerous diseases resulting from it. According to Douglas (1996:106), "if a group of individuals ignore some manifest risks, it must be because their social network encourages them to do so," and one may therefore assume that their social interaction "does a large part of the perceptual coding on risks."

Risk acceptability or perception is often independent of practical definitions or empirical judgments. For Douglas and Wildavsky (1982: 6 and 80 ), the concept of risk has helped promote the notion of insecurity, within which people act according to socially accepted parameters rather than based on knowledge. Thus, the risk can be seen as a social category, an effect of the interaction between fear and confidence.

Douglas supports the idea that one cannot speak of experts in risk acceptability, because there is no higher authority to identify and assess risks. Douglas and Wildavsky (1982) argue that the opinion of the lay public on risks should be as highly valued as that of experts. The main issue is that experts, from their offices, cannot ignore the social dimension of risks; the scientific method of risk assessment should take into account "public participation" in decisionmaking with regard to risk.

When developing the theory on natural risks, Douglas (1996:89) argues that "the cultural processes which select certain kinds of dangers for attention work through institutional procedures for allocating responsibility. Blaming the victim, blaming the victim's parents, or blaming the outsider are well-known strategies." That is to say that people act according to socially acceptable parameters rather than based on their knowledge of risk perception; moreover, it is society that defines what is risky through its institutions. The author suggests that transferring responsibility or blaming the victim is often effective for attenuating conflicts and silencing indictments of the whole social system. Faced with a catastrophic event, institutions tend to pin the blame on "public sectors" in order to minimize their problems before the society. In our concrete case, involving the death of tons of fish in the Sinos River (October 2006), there remains controversy over whom to blame for the disaster: some point to the lack of treatment of domestic waste and others of industrial waste; this allows us to state that a choice of either of the hypotheses is based on attributing blame to an institution other than that to which each one belongs. Based 
on evidence from reports made by technicians, it appears that they supposedly have a vested interest in defending the institution for which they work. Due to the concealment of the truth by some, there is a tendency to discredit the science and the people involved in the case.

In summary, the anthropological approach developed by Mary Douglas is directly related to the interest of social sciences in shaping the concept of risk, aiming to identify, in discourses and social practices, the dangers and uncertainties of contemporary life choices. Both Giddens (1997) and Douglas and Wildavsky (1982) discuss this concern and suggest that risks are less related to real threats to human life than to rationalities, interests and cultural patterns; for the authors, they are a source of social issues.

We can conclude that Douglas does not address the issue of risk and risk acceptability outside a social and political context. This reading has already been proposed in the past by Weber, and more recently by other authors who follow the same argument, such as Beck, Guiddens, and Enrique Laraña, among others. Individual perceptions encourage the understanding of risks as a social construction; when individuals make a decision, they evaluate probabilities, assumptions and credibility, including a construction of values rooted in their cultural development.

\section{MATERIALS AND METHODS}

This investigation analyzes the perception and action of environmental risks in the Sinos Valley, state of Rio Grande do Sul, Brazil. The interest in this case is justified by the fact that the development of the tanning industry promoted the sociocultural and historical construction of the Sinos Valley. The Sinos Valley is a critical industrial region with social and environmental vulnerability; thus, this investigation leads us to reflect on the perception of different actors (sociocultural, economic, political) about the risks posed by tanneries to the environment and, especially, to determine whether the indifference indicates lack of interest or is a consequence of the dependence of the local economy on industrial development.

The present case study legitimizes itself not only by this development but also by its consequences for the environment, particularly due to perception of risk [or lack of it] that, along with other factors, contributes to the death and destruction of nature in the region. The investigation is based on 32 open interviews; on 307 surveys with sociocultural, economic and political actors (96 workers, 56 representatives of public administration, 84 neighbors, 36 representatives of tanneries and 35 technicians); and on observation and document review. Interviewees are affiliated with sociocultural, economic and political agents. The interviewed subjects were divided into: workers, former workers, representatives of public administration, NGOs, neighbors and industrialists related to the tanning industry, and interviews emphasized actors' personal experiences, their feelings, how they perceive risks, how they interact, and especially what actions they take with regard to risks.

The analysis of the interviews focused on the actors, considering a sub-sample of one of every three interviews (1-3), depending on the number of interviewees. On the other hand, although the analysis was fragmented into three segments (sociocultural, economic and political), the analysis regarding environmental risk perception-action was integrated. The intention was not limiting the investigation to specific quotations or to those that depend on the segment to which the interviewee belongs; that is, we intended to perform a systemic analysis. The selection of this strategy (1-3) was previously motivated by an important dilemma: 1- if we choose to "mention" the majority of the interviews (interviewed actors), there is the risk of looking for "fragments of quotes" with the purpose of confirming the previous assumptions of the investigation; 2- if we choose to analyze the 
transcript of a percentage (1-3) of the interviewed actors and simplify the discourse, it could lead to misunderstandings resulting from generalizing something that is actually specific.

The choice for the second option (2) was based on the principle that, since this is a qualitative investigation, it should focus on interviewees' feelings, values, perceptions and actions. We believe that, when dealing with a qualitative analysis, the amount or equality of the statements reported by interviewees is not the most important or conclusive aspect, but rather the agreement or discrepancy in the comparison among actors. Thus, we present below the basis of our analysis, which was the sub-sample of interviews divided into interviewed segments (13 ). It does not mean that the remaining interviews were not analyzed, since one will be able to see that the text quotes other interviewees, but these were the minority of quotations:

\section{Workers:}

Int. 1, Worker A. Int. 3, Worker (Technician) C. Int.11, Public Admin. C. Int. 8, Worker $\mathrm{H}$.

\section{NGOS}

Int. 18, Association A. Int. 19, Association B. Int. 20, Association C.

\section{Industrialists or Representatives of the industry}

Int. 26, Business Person A.

Int. 27, Business Person D.

Int. 32, Business Person G.

As shown above, surveys were applied in addition to interviews. The importance of the surveys lies on the fact that they allow for a comparative analysis between data from open interviews. The intention was not performing a quantitative or statistical analysis, but rather to use an additional technique to confirm or refute the data obtained with the qualitative method. In this case, the application of a survey (closed) was appropriate to explicitly depurate interviewees' opinions and attitudes, because they were asked exactly what we sought to confirm, based on the goals proposed by the investigation and on the data obtained so far. Finally, this technique was important to prove the initial assumptions, providing rates for comparison and analysis with the remaining data.

\section{RESULTS AND DISCUSSION}

Perception, VALUES AND ATtitudes: Sociocultural CONSTRUCTION OF RISKS IN THE SINOS VALLEY, BRAZIL

The issue of risks has stimulated a new debate within the social reality on the planning, boundaries and actions to be taken in view of the development of industrial technology. In parallel with this debate, an interest has emerged concerning the sociocultural aspects of values and risk perception. According to Beck (1997) and Douglas (1992), one or more risks may be perceived and judged differently, depending on the social environment in which an individual is located. These perceptions are part of a cultural complex that is hardly expressed in a transparent manner. Although for many people subjectivity is simple and free to interpretation, here it is judged with great responsibility, trying to transcribe the feelings and values of the community agents of the Sinos Valley in relation to risks.

Following a constructivist approach, risks refer to personal, social and cultural aspects, with an emphasis on subjective risk perception. Puy (1995) argues that for the social sciences it is difficult to conceptualize (or analyze) risks other than a social construction that takes into account what people consider when judging a risk.

"(...) based on a constructivist concept, the cultural theory of risk offers an interpretation of the social experience of risk, without falling into the trap of arbitrariness that characterizes several sociological analyses inspired by the 
same philosophy. This may provide additional evidence to support the importance of cultural factors in risk perception and risk policies. It also provides a useful complementary explanation for social actions that appear to conflict with technical analyses or the interests of an initiation group." [Our translation] (Garcia 2004:200).

The interpretation of risks is diverging and their construction depends on the values and needs that are assigned by assuming a risk, along with feelings of being able to intervene (or not), certainties and uncertainties, and the perception of threat or damage. Yates and Stone (1992:23) propose three components for the notion of risk: "losses, the significance of losses and the uncertainty associated with a particular loss."

The losses are based on references that individuals (or groups) have with regard to their expectations, values, current and past experience. These references may vary for different people and contexts. This is expressed in the social and historical construction of the studied region (Sinos Valley), where the behavior in relation to risks is reflected in lifestyle habits acquired in the past.

The significance of losses covaries positively with the overall risk (Puy 1995:10), unlike what Yates and Stone suggest as the significance of individual decisions. According to Puy (based on Yates and Stone's theory), a framework of attitudes, values, motivations, expectations, and past experiences, among others, is determined by social and cultural aspects as a prevailing belief, which determines political decisions and is essential for the study of risk perception; corroborating the idea of Mary Douglas, as previously discussed.

The last component that adjusts the overall analysis of risk is uncertainty. According to Puy (1995), the greater the uncertainty about which areas might be affected by losses, the greater the risk. $\mathrm{He}$ argues that the greater public ignorance about a situation of loss, the greater the risk; "the level of uncertainty concerns the degree of confidence that determines or estimates the probability of loss" [our translation] (Puy 1995:12).

Regarding the first components (losses and significance of losses), it can be determined that the region of the Sinos Valley was constructed within an industrial environment; the cities were mostly established around footwear industries and tanneries. People live or have chosen to live in this environment motivated by the availability of jobs, a desire to work and to continue an industrial tradition inherited from their predecessors. Such a position is expressed in all segments surveyed, as described in the following transcript, which establishes a cultural connection by comparing the German immigration in the Sinos Valley and the culture in mountain areas (Italian immigration).

"The German culture is only leather and shoes and they will 'die clasped together.' If you go to the mountains, you can find the gringos [Italians]: wine, tourism, hotels, furniture, handicrafts, mechanics, etc. They diversify from their core business, getting stronger; the economy does not depend on a single sector. I myself am an example of tradition, my grandfather knows how to make shoes, my great-grandfather was a tanner, and so are my father and many other people. (...) I talk to business people and ask why they do not invest in other things, and the answer is: my father used to do this, I will go on with it; maybe my son will not do it, who knows?" (Interview 3 with worker - technician C.)

Figures 1 and 2 show that most people from the community work in a tannery motivated by the social and historical development of the region, they are strongly influenced by an activity that has been performed for years in their family, and as a matter of frequency or routine, 
most people state that they are happy with and want to do this work. Another important feature (Figure 1) is that, although most interviewees state that they are happy with this activity, a great part of the people indicates that they do not work in a different area because there are no jobs available. This confirms that the economy in the Sinos Valley concentrates in a small range (leather and footwear), which may be an important indicator that, due to the inability to change jobs, the workers do not speak out against this activity.

Following the analysis of Puy (1995) regarding uncertainty, there is a conflict between popular and scientific knowledge. Moreover, when there are losses, such as in the case of the environmental disaster resulting in the death of fish, the risks are generalized and, as a consequence, individuals argue that they are faced with a lower probability of employment. Although

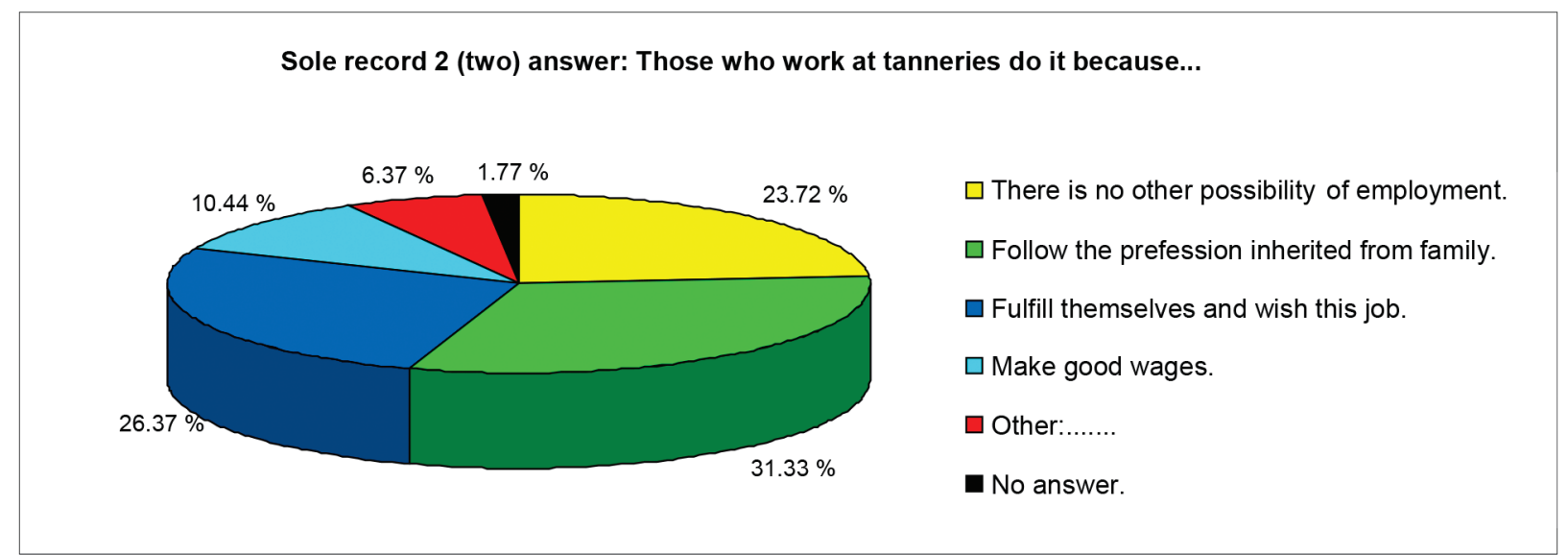

Source: Survey with representatives of public administration and with several managers, workers, technicians and neighbors of tanning industries, 2006-2007. Own elaboration.

Figure 1 - Motivation to work at tanneries.

Do tanneries still exist in Vale do Rio do Sinos because they are part of a historical-cultural heritage?

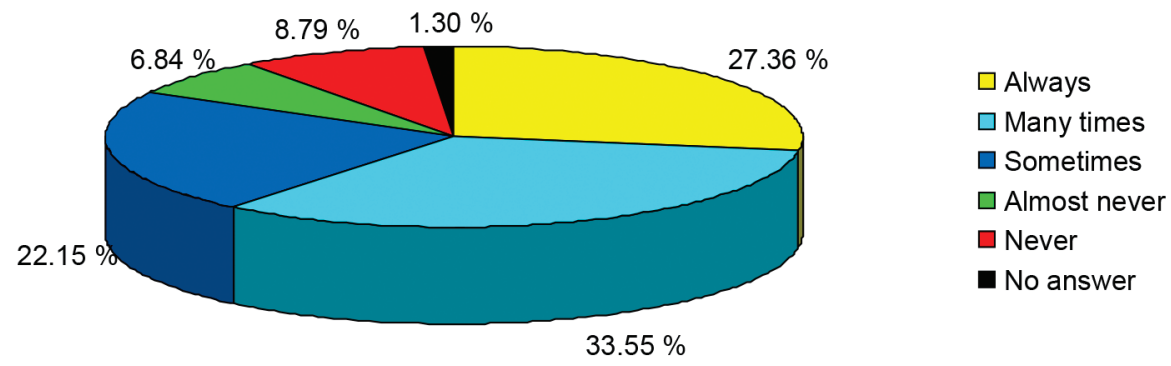

Source: Survey with representatives of public administration and with several managers, workers, technicians and neighbors of tanning industries, 2006-2007. Own elaboration.

Figure 2 - Historical-cultural relationship of the tanning industry. 
the documents have been issued by the institutions, it is important to compare the reports by FEPAM (Fundação Estadual de Proteção Ambiental "State Environmental Protection Foundation" 2010) and by FIERGS (Federação das Indústrias do Estado do Rio Grande do Sul "Federation of Indutries of the State of Rio Grande do Sul" 2010) on the death of fish. One can note a strong tendency to blame other parties for self-defense. Most workers deny the risks and defend themselves based on past experiences of people who were engaged in this labor activity; perhaps it is interesting to question why workers tend to blame domestic waste rather than industrial waste; as discussed later, this point may be related to the maintenance of jobs, which is way they say they do not have health problems.

"I left school and started working at the age of 14 in a tannery, I have gone through all sectors (...) during the years 1975/76 I worked with several chemicals, such as sodium sulfate, calcium oxide, and sulfuric acid, always without gloves, without anything; just as my father did, there was no protection. I have been working for 30 years in a tannery, but I usually say that I have been 'inside' a tannery since the age of 5/6; we used to play around the leather shelves where my father worked; in fact, our entire family worked in a tannery, even my sister, who is now a teacher, also began in the tanneries." (Interview 8 with worker $\mathrm{H}$ ).

It is worth noting a statement by a public administration representative, which stands out among others; the representative is convinced that the chemicals used in the tanning industry do not cause hazards to health: "if chemicals caused any harm, many people would have already died, or many people would be ill, and this would have already been reported by the media."

At another point, the interviewee explains that when he was younger he did not fear to have any problems with chemicals and their adverse effects on health; he was only looking for work and a source of income. He also mentions his father's working life, who has also been an employee in the tanning industry for his whole life. In addition to this (cognitive) assessment, it is possible to identify that the society of the Sinos Valley is influenced by a system of values that (re)produce the experience of others with regard to what may or may not be a risk.

The social construction of industrial processes lowers the risks, since the people do not identify themselves as victims (Douglas 1996). Wildavsky and Dake (1990) argue that individuals organize their own perceptions on what to "fear" in order to support their way of life. According to the authors, such an acceptance responds to cultural biases: ideologies consisting of values and beliefs to defend social patterns. This is to say that the population from the Sinos Valley is selecting the risks that they will fear in order to give coherence to their lives, ignoring the (real) risks in order to follow their own values. In this way, Douglas states that the acceptance of risks is diverging, depending on the social groups; some tanneries located in other Brazilian states (e.g., in the state of Pará) are causing protests from the local population, i.e., the same risks that are not relevant to the population from the Sinos Valley appear to be relevant to other populations.

We may speculate that the lack of a civil society's identification of hazards would induce the population to disregard the real risks, lead to a lack of motivation, or even to a lack of interest in planning management strategies and integrated policies to fight environmental degradation, a situation that has been long considered urgent by the institutions responsible for the environment. Conversely, one might question, what is the meaning behind that nonsense, a belief that advances without limits, causing death and destruction?

The lack of organization or mobilization may be the main reason for the nonsense observed in the Sinos Valley. In the absence of groups, there 
are no protests; thus, the awareness of certain dangers is reduced, translating into individualized public responses to risk. Complaints can be made by telephone to municipal services (environmental protection agencies) or NGOs, with no identification of callers. According to an interviewee (member of an association), after the death of fish and frequent problems related to industrial pollution in the Sinos River, a hotline was established so that people could make their complaints. In the interviewee's opinion, "people are afraid to express themselves publicly and this is a problem, there is no protest." The quote below (phone calls recorded by an NGO) shows that, although in a small proportion, there is a perception of risk, but this is still an individual perception that lacks strength to create a collective awareness of risk. Calls were received between October 11 and 15, 2006. Some of the documented complaints were selected, mainly those about tanning industries. The citation of fragments of quotes is important to establish a relationship with the assumptions developed so far about the risks posed by the tanning industry to the environment. The statements (complaints) are in accordance with the extracts provided by the NGO and what was expressed by the callers:

"The company disposes chemicals into the creek and FEPAM accepts bribes from the company." [This caller is a neighbor who states that his wife has witnessed the fact.]

"The company disposes effluents into a nearby stream that runs through other lands where there are animals; two cows died and the owner of the company paid an amount equivalent to ten cows for silence. The owner carries a gun and threatens people." [A great fear of the caller could be noted, because she could be putting her life at risk if her telephone call was identified - it was an anonymous phone call, received and written down between 11 th and 15th of October 2006].
[The caller from a NGO says that he carries out maintenance work on tanning equipment]. "They have a clandestine underground piping system and some industries dump their waste straight into the creek. Treating waste is expensive, so they discharge waste directly into the creeks even if they have a treatment station to do so." [Anonymous phone call, received and written down between 11 th and 15 th of October 2006].

"When FEPAM inspectors arrive in the company, they are distracted at the front desk [at the reception of the company], while the pipes of the treatment station are changed, because the correct is to proceed through activated charcoal, but they only do that when FEPAM inspectors show up. Many times the mud goes straight into the creek." [Anonymous phone call, received and written down between 11 th and 15th of October 2006].

"Pampa creek, on Curitibanos street at Florença street, close to number..., they are taking it now, it is raining." [The caller speaks very fast and hangs up, he was also an anonymous phone call, received and written down between 11 th and 15th of October 2006].

According to a report by this NGO, callers usually were: employees, relatives of employees, former employees, people living close to the industries, retired people, and workers who provide maintenance services (technicians). Most callers required public agencies to do something after the tragedy.

These complaints justify and support the responses obtained so far in this investigation on the risk perception-action of the tanning industry in the Sinos Valley: accountability of public administration as an inspection agency, minimizing the responsibility of the industries; fear of losing jobs and retaliation; individualized actions as a manifestation or protest. Nevertheless, the analysis of these complaints led to reflection and, in some 
way, also led to a conflict with the assumption of non-identifying the risks added up during the sociocultural construction of the Sinos Valley.

One may say that there is an inversion of the traditional sociology of conflict, i.e., the individual awareness of risk is not sufficient to give rise to environmental groups or associations for social mobilization. It is observed that the existence of these groups acts as a symbolic message for the collective awareness of risk. In the present case, because there are no such groups, there is no awareness of risk. Instead, there are groups that prevent this awareness and organizations that hold back the (environmental) movement: groups that manifest themselves in defense of jobs. We draw attention to the following statement from an interview with a business person: "(...) this is part of the Brazilian culture; when protests happen, they are conducted in a particular way, by calling public agencies and making complaints. Brazilians are passive and have no organizational skills."

Groups that might motivate mobilization are disengaged or acting individually and occasionally. We do not refer to movements that appear and disappear (the boomerang effect of new social movements), but rather to the fact that they are disorganized groups, without continuous participation of the population. They emerge momentarily in response to catastrophic events, which are visible to society, such as in the case of the death of fish in the Sinos River (October 2006). The low level of engagement in the movement by residents and workers is one of the main problems in the Sinos Valley. This becomes evident in the case of the death of fish, when some movements hired advertising space to publicize the dead fish issue and to call the community to participate in a protest. However, the actions relied on very few elements of organization, as many people participated without knowing the name and goals of the association - an example is described below.
"UPAN can close the Highway 116 for a protest.

As of 11 am today, the Union for the Protection of the Natural Environment (UPAN) promotes a protest in the Sinos River in front of Sao Leopoldo bus station. The Highway 116 may be closed. (...) The whole community is summoned to attend the protest." (Sinos Valley newspaper, 26-10-2006)

The case studies by Laraña (2002, 2004) present a structure where there are mobilizations and groups that identify risks. According to Laraña, organizations are the ones to produce a sense; however, there are no organized groups in the Sinos Valley (movements or associations) to protest. Therefore, it is not possible to analyze this case from the perspective of mobilizations and risks, since it was found that the existing groups are not sufficient to lead to mobilization and awareness of risk.

Finally, we observe a conflict in the perception of risk: on the one hand, some people manifest themselves individually and in a "hidden" manner, without generating mobilization, while others defend their jobs and industrial development, minimizing risk perception to support private interests.

\section{CONCLUSION}

We conclude that risk perception is directly related to human behavior, because physical events are captured by all senses and processed in a way to relate and compare them with past experiences, thus assigning a meaning to all new events. This meaning, in turn, is not only the result of an individual construction, but rather a sociocultural product that integrates economy, politics, psychology, and environment, among other factors. In the case of the tanneries in the Sinos Valley, although the strong impact of this industrial activity on the environment and health has been institutionalized and acknowledged by the scientific community and responsible agencies, this is not sufficient to change the symbols that have been constructed collectively throughout the history. 
It is established that there is no universal condition in the issue of risks, but risk perception is conditioned to the external and internal context of individuals, i.e., to the social group they belong. With regard to the case investigated here, the (external) aspects of historical and cultural construction are directly associated with the development of the leather and footwear industry, which have been crucial in the allocation of values, principles, perception and inner attitude regarding the risks posed by this industrial activities.

The sociocultural formation of the Sinos Valley legitimates the development of the region as a result of the progress of the leather-footwear industry. It is worth noting that behind this history there are basic issues related to population survival, i.e., both the industrialists and workers establish partnerships when they create a movement against the leather industry. The values of the union movement are reversed; they no longer claim for salary increase, but rather for the company to continue operating, and workers often lower their demands to remain employed. Thus, we observe a society that, in its current historical moment, cannot be thought in the long term. People are motivated solely by meeting their basic needs; the success or failure of people living within this urban-industrial complex is measured by whether they have a job or not. Most workers deny or ignore current risks blinded by the memories of a time when the industry provided jobs for their parents and grandparents.

In a certain way, it is not possible to hide such facts when seeking to investigate the formation process of the Sinos Valley, as it is established that this community, since its inception, has prioritized industrialization as the main means of development. The impact of industrialization on the environment and health has always been obliterated by economic interests and population growth in the region, both symbols of progress. For several decades, the government has conformed to the principles and wishes of the private sector (increase in the number of industries) and, in part, of the collectivity (job offers). People have been conditioned by an industrial culture that has spared no effort to be considered the largest industrial complex in Brazil within the "leather industry." Before there was not much concern about the environment, natural resources were described as in excellent condition; a win-win situation: the employees, with good wages and job options; the industry, with good profits; and the government, considered good for the population by promoting development in the region. As a consequence, governments now "pay the debt" of the irresponsibility of the past: from the triumph of employment to the failure of unemployment, from the protection to destruction of the environment, in addition to government attitudes that have affected employment opportunities, leading to a rejection by the community. Pollution caused by industry may be accepted by governments in order to ensure popularity, since protest movements in the region have been more articulated to speak out in defense of jobs than against pollution problems.

\section{RESUMO}

A proposta de análise da percepção socioambiental será desenvolvida a partir do discurso como elemento constitutivo da realidade. As práticas discursivas e sua concretização serão a fonte de significado e de valor sociocultural. Desta forma, o método de pesquisa escolhido foi o estudo de caso qualitativo e quantitativo. Na primeira parte do texto retomaremos o aporte teórico de Mary Douglas sobre risco e cultura, e também sobre a aceitabilidade dos riscos na sociedade. Na segunda parte, trataremos de alguns dados do caso dos riscos provenientes da indústria curtidora e de como a sociedade do "Vale do Rio dos Sinos" se relaciona com esses riscos. Assim, neste artigo, podemos concluir que a percepção de risco da população está diretamente relacionada com as experiências passadas, atribuindo assim um sentido para todos os novos eventos. Este significado é o resultado de uma construção sociocultural. É interessante notar que por trás dessa história há questões básicas 
relacionadas com a sobrevivência da população, ou seja, tanto os industriais quanto os trabalhadores estabelecem parcerias quando a sociedade cria um movimento contra a indústria do couro.

Palavras-chave: risco ambiental, percepção do risco, poluição hidrográfica, indústria coureiro calçadista.

\section{REFERENCES}

BECK U. 1997. La reinvención de la política: hacía una teoría de la modernización reflexiva. In: GIDDENS A, BECK U and LASH S (Eds), Modernización Reflexiva: política, tradición y estética en el orden social moderno, Madrid: Alianza.

DougLAS M. 1992. Risk and blame: essays in cultural theory, London: New York, Routledge.

Douglas M. 1996. La aceptabilidad del riesgo según las ciencias sociales, Barcelona: Paidós.

Douglas M AND WiLDAVSKY A. 1982. Risk and culture: an essay on the selection of technical and environmental dangers, Berkeley, Los Angeles: University of California Press.
FEPAM - FUNDAÇÃo DE ESTADUAL DE PROTEÇÃO AMBIENTAL. 2010. Available in: <http://www.fepam.rs.gov.br>. Acessed in: 25/5/2010

FIERGS - FEDERAÇÃO DAS INDÚSTRIAS DO ESTADO DO RIO GRANDE DO SUL. 2010. Available in: <http://www.fiergs. org.br>. Accessed: 25/5/2010.

GARCIA HA. 2004. Negociar el Riesgo, Barcelona: Ariel.

GIDDENS A. 1997. Vivir en una sociedad postradicional. In: GIDDENS AAND LARAÑA E (Eds), La construcción de los movimientos sociales, 1999, Madrid: Alianza Editorial, S.A.

LARAÑA E. 2002. La construcción social de discursos rivales sobre el riesgo. Modernización y acción colectiva. En: ROBLES JM (Eds), El reto de la participación. Movimientos sociales y organizaciones: una panorámica comparativa, Madrid: Machado Libros, S.A.

LARAÑA E. 2004. Participación pública y nuevos conflictos sociales desde la sociología del riesgo. En: Rev Psicol Política, $n^{\circ} .4$.

PUY A. 1995. Percepción Social de los Riesgos, Madrid: Mapfre.

WILDAVSKY A AND DAKE K. 1990. Theories of Risk Perception: Who fears what and why 119(4): 41-60.

YATES FJ AND STONE ER. 1992. The risk construct. In: Yates FJ (Eds), Risk-taking Behavior, Wiley: Chichester, p. 1-25. 